\title{
Temperature Dependence of Young's Modulus and Internal Friction in Sn-Zn-Al Lead-Free Solder"
}

\author{
Yasumasa FUJII $^{* *}$ and Teruaki ONO ${ }^{* *}$ \\ ${ }^{* *}$ Department of Mechanical and Systems Engineering, Faculty of Engineering, Gifu University, \\ 1-1 Yanagido, Gifu-city, Gifu 501-1193, Japan \\ E-mail: ono@gifu-u.ac.jp
}

\begin{abstract}
There have hardly been experimental studies of the mechanical properties of Sn-7Zn-0.006Al lead-free solder. The temperature dependence of Young's modulus $E$ and internal friction $Q^{-1}$ were investigated in $\mathrm{Sn}-7 \mathrm{Zn}-0.006 \mathrm{Al}$, $\mathrm{Sn}-7 \mathrm{Zn}$, and $\mathrm{Sn}-8 \mathrm{Zn}-3 \mathrm{Bi}$ solders using flexural vibration. Sn-7Zn-0.006Al solder showed the smallest $E$ drop with increasing temperature, representing heat-softenig. Three $Q^{-1}$ peaks appeared at around $90-100^{\circ} \mathrm{C}\left(1^{\text {st }}\right), 135-140^{\circ}\left(2^{\text {nd }}\right)$, and $175-180^{\circ} \mathrm{C}\left(3^{\text {rd }}\right)$ in $\mathrm{Sn}-7 \mathrm{Zn}-0.006 \mathrm{Al}$ and $\mathrm{Sn}-7 \mathrm{Zn}$, and two $Q^{-1}$ peaks at around $90^{\circ} \mathrm{C}\left(1^{\text {st }}\right)$ and $135^{\circ} \mathrm{C}\left(2^{\text {nd }}\right)$ in $\mathrm{Sn}-8 \mathrm{Zn}-3 \mathrm{Bi}$. To investigate the origin of these $Q^{-1}$ peaks, vibration experiments at lower frequencies were also carried out. From Arrhenius plots for the $Q^{-1}$ peaks in two vibration experiments, the $3^{\text {rd }} Q^{-1}$ peak in Sn-7Zn-0.006Al, the $2^{\text {nd }} Q^{-1}$ peak in $\mathrm{Sn}-7 \mathrm{Zn}$ and those at low frequencies in $\mathrm{Sn}-8 \mathrm{Zn}-3 \mathrm{Bi}$ were relaxation phenomena obeying the Arrhenius equation, whose activation energies were determined to be $83 \mathrm{~kJ} / \mathrm{mol}, 144 \mathrm{~kJ} / \mathrm{mol}$, and $98 \mathrm{~kJ} / \mathrm{mol}$, respectively. It was estimated that the origin of these $Q^{-1}$ peaks was related to the grain boundary from these values, and that $\mathrm{Sn}-7 \mathrm{Zn}-0.006 \mathrm{Al}$ alloy was refined in microstructure by the addition of a very small amount of $\mathrm{Al}$ and superior to other $\mathrm{Sn}-\mathrm{Zn}$ system solders with regard to mechanical properties.
\end{abstract}

Key words: Sn-7Zn-0.006Al Solder, Temperature Dependence, Young's Modulus, Internal Friction, Activation Energy

\section{Introduction}

A number of lead-free solders have been developed and the mechanical properties, which are influenced considerably by microstructure, are important for solders. An elastic modulus of them is measured unjustly low in static methods, because the large elastic strain and creep occur easily in a solder to be a soft alloy. On the contrary, in vibrational methods, generally the stain is small and no creep occurs; furthermore, the internal friction, which is useful for the discussion on microstructure, can be measured. Therefore, it has been used well in the field of metal physics. However, in vibrational methods, it is necessary to investigate the effect of measurement frequencies on them, because a solder is an anelastic body. Firstly, the dependence of frequency on Young's modulus and internal friction in Sn-9Zn and Sn-3.5Ag eutectic lead-free solders was investigated in our paper (2004) ${ }^{(1)}$ using vibration and static methods. The temperature dependence of mechanical properties is very important for solders. In such experiment, internal friction peaks occur at temperatures where some change happens to microstructure, and assuming relaxation phenomena to 
apply to the Arrhenius equation, activation energy can be obtained from some internal friction peaks at different temperatures measured at large different frequencies, then the origin of internal friction peaks can be discussed on microstructures. For these purposes, secondly, the temperature dependence of anelastic properties in $\mathrm{Sn}-\mathrm{Ag}-\mathrm{Cu}$ system, which is now becoming the global standard lead-free solder, and $\mathrm{Sn}-3.5 \mathrm{Ag}$ alloys was investigated in our previous paper $(2005){ }^{(2)}$ using vibration apparatuses in an audio-frequency range by us and in a low frequency range by a maker.

$\mathrm{Sn}-\mathrm{Zn}$ solder has the advantages of lower melting point, close to that of $\mathrm{Sn}-\mathrm{Pb}$ solder, lower cost, and richer resource availability. However, Sn-Zn solder has the problem of low wettability because of high oxidization due to its high reactivity. The ternary alloy of $\mathrm{Sn}-\mathrm{Zn}-\mathrm{Bi}$ has been developed to improve this property. However, the addition of $\mathrm{Bi}$ to $\mathrm{Sn}-\mathrm{Zn}$ alloy adversely affects the mechanical properties. The Sn-7Zn-0.006Al lead-free solder with addition of a very small amount of $\mathrm{Al}$, in which the oxidation of $\mathrm{Zn}$ is suppressed by forming a layer of $\mathrm{Al}$ oxide on the surface, was proposed by Kitajima et al. (2002) ${ }^{(3)}$. The mechanical properties of Sn-7Zn-0.006Al and the differences in these properties between $\mathrm{Sn-7Zn-0.006Al}$ solder and $\mathrm{Sn}-\mathrm{Zn}$ and $\mathrm{Sn}-\mathrm{Zn}-\mathrm{Bi}$ solders are of great interest, but little information is currently available.

In this study, the temperature dependence of Young's modulus and internal friction were measured for $\mathrm{Sn}-7 \mathrm{Zn}-0.006 \mathrm{Al}, \mathrm{Sn}-7 \mathrm{Zn}$, and $\mathrm{Sn}-8 \mathrm{Zn}-3 \mathrm{Bi}$ solders and the difference between them and the effects of additives were investigated; furthermore, vibration experiments at lower frequencies were also carried out to discuss the origin of internal friction peaks appearing in the temperature characteristics of flexural vibration, in the same way as our previous paper $(2005)^{(2)}$.

\section{Experimental}

\subsection{Samples and Specimens}

The samples were Sn-7Zn-0.006Al, Sn-7Zn, and Sn-8Zn-3Bi alloys with melting points $\left(T_{\mathrm{m}}\right)$ of $200^{\circ} \mathrm{C}, 200^{\circ} \mathrm{C}$, and $195^{\circ} \mathrm{C}$, respectively. They were melted at a temperature of $\left(T_{\mathrm{m}}+100^{\circ} \mathrm{C}\right)$ in an electric furnace with addition of a small amount of flux $\left(75 \mathrm{wt} \% \mathrm{ZnCl}_{2}+\right.$ $25 \mathrm{wt} \% \mathrm{NH}_{4} \mathrm{Cl}$ ). Test specimens were made by pouring the melts into molds heated to about $120^{\circ} \mathrm{C}$ to obtain a smooth surface. The sizes of test specimens, with a rectangular bar shape, used for resonant flexural vibration and non-resonant flexural vibration were $80(l) \times 5(w)$ $\times 3(t) \mathrm{mm}$ and $65(l) \times 5(w) \times 2(t) \mathrm{mm}$, respectively. The densities of the $\mathrm{Sn}-7 \mathrm{Zn}$, $\mathrm{Sn}-7 \mathrm{Zn}-0.006 \mathrm{Al}$, and Sn-8Zn-3Bi specimens were measured by the Archimedean method, and were $7.22-7.28 \mathrm{~g} / \mathrm{cm}^{3}, 7.23-7.28 \mathrm{~g} / \mathrm{cm}^{3}$, and $7.29-7.33 \mathrm{~g} / \mathrm{cm}^{3}$, respectively, which were in the relative error range of $0.1-0.8 \%$ for their theoretical densities.

\subsection{Measuring Method}

The flexural vibration experiments were performed in an electric drying oven. A free-free bar specimen was excited in fundamental mode by an electromagnetic transducer set facing its center where a small piece of iron was glued, and vibration sound guided out of the oven by a glass pipe was detected with a condenser microphone. The values of resonance frequency $f_{0}$ and internal friction $Q^{-1}$ were obtained from the peak and half-value width of the resonance curve, respectively. Generally, dynamic Young's modulus $E$ is calculated from the following Eq. (1):

$$
E=\frac{48 \pi^{2} \rho l^{4} f_{0}^{2}}{m^{4} a^{2}}
$$

Where, $\rho$ is the density, $l$ is the sample length, $a$ is the sample thickness, and $m$ is a constant (4.730 at 1 st mode). However, as the test specimen expands on heating in this experiment, it 
is very difficult to determine the dimensions and density accurately. In contrast, $f_{0}^{2}$ can be determined with a high degree of accuracy of $0.1 \%$. In this experiment, $f_{0}^{2}$ was used instead of $E^{(2)}$. The measurement frequency range was about 900-1300 Hz. Measurements were carried out by gradually increasing the temperature from room temperature $\left(T_{\mathrm{R}}\right)$ to close to $T_{\mathrm{m}}$ at a rate of $1^{\circ} \mathrm{C} / \mathrm{min}$. After measuring at intervals of $5-10^{\circ} \mathrm{C}$, the same experiment was performed again to investigate the effects of heat history. The temperature indicated by a digital thermometer was calibrated with a standard thermometer.

Furthermore, $E$ and loss tangent, $\tan \delta\left(=Q^{-1}\right)$, were measured with excitation vibrations of $1,5,10,50$, and $100 \mathrm{~Hz}$ at the center of a dual cantilever using a dynamic mechanical analyzer (DMA) (TA Instruments Co., Crawley, UK). The specimens were fixed at a span of $43 \mathrm{~mm}$ and the vibration amplitude was set to $10 \mu \mathrm{m}$, and the temperature was increased to close to $T_{\mathrm{m}}$ at a rate of $2^{\circ} \mathrm{C} / \mathrm{min}$.

\section{Results and Discussion}

Measurement examples for each of solder by resonant flexural vibration are shown in Fig. 1. The Young's modulus at $T_{\mathrm{R}}$ is shown in the figure. In all the solders, the $f^{2}$ decreased and the $Q^{-1}$ increased with increasing temperature. Three $Q^{-1}$ peaks appeared at around $90-100^{\circ} \mathrm{C}\left(1^{\text {st }}\right), 135-140^{\circ}\left(2^{\text {nd }}\right)$, and $175-180^{\circ} \mathrm{C}\left(3^{\text {rd }}\right)$ in Sn-7Zn-0.006Al and Sn-7Zn, and two $Q^{-1}$ peaks at around $90^{\circ} \mathrm{C}\left(1^{\text {st }}\right)$ and $135^{\circ} \mathrm{C}\left(2^{\text {nd }}\right)$ in $\mathrm{Sn}-8 \mathrm{Zn}-3 \mathrm{Bi}$. In comparison of the first measurement with the second measurement, by heating again, the $f^{2}$ increased slightly and the $Q^{-1}$ decreased in the high temperature range where $Q^{-1}$ was large. This was thought to be due to the rearrangement of atoms by the first measurement functioning as the heat treatment effect. From the first measurement, the rate decrease in $f^{2}$ with increasing temperature from $30^{\circ} \mathrm{C}$ to $180^{\circ} \mathrm{C}$, showing almost a straight line, was highest for

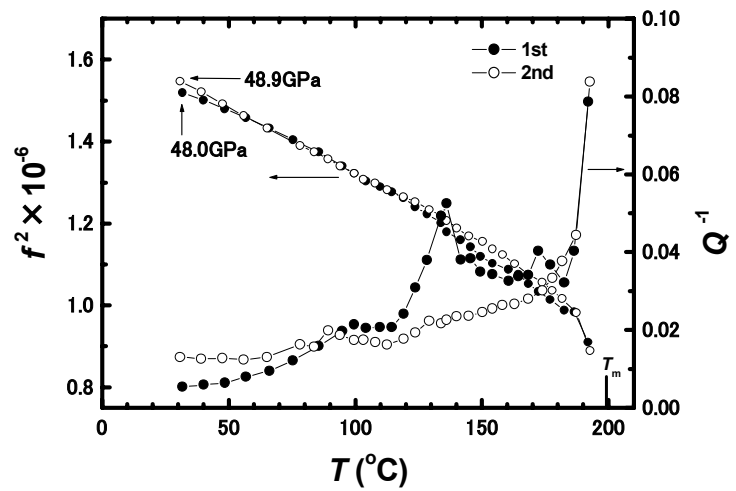

(a) $\mathrm{Sn}-7 \mathrm{Zn}$

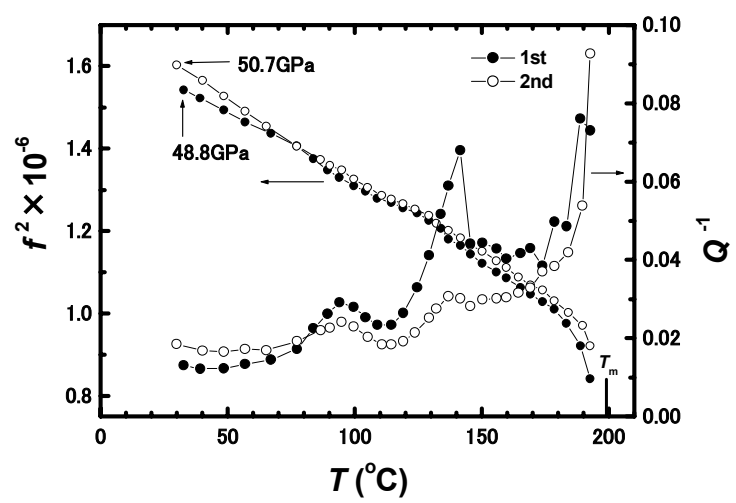

(b) $\mathrm{Sn}-7 \mathrm{Zn}-0.006 \mathrm{Al}$ 


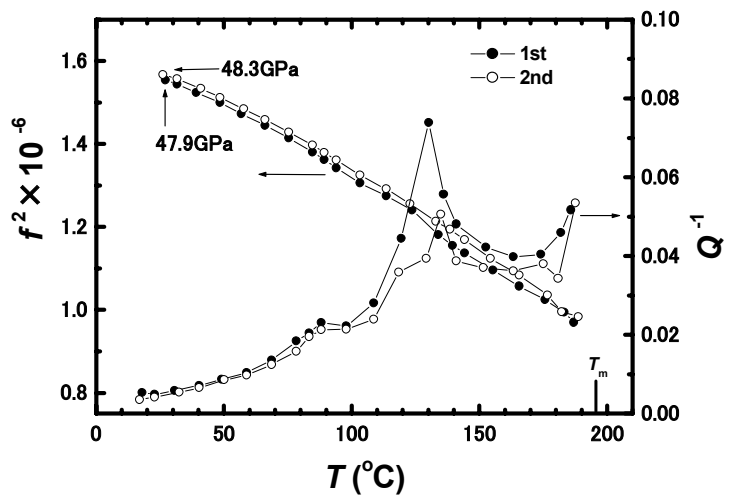

(c) $\mathrm{Sn}-8 \mathrm{Zn}-3 \mathrm{Bi}$

Fig.1 Temperature dependence of the square of resonant frequency $f^{2}$ and internal friction $Q^{-1}$ by flexural vibration.

Sn-8Zn-3Bi (35.5\%), followed by Sn-7Zn (34.9\%), and the smallest value (34.5\%) was observed with $\mathrm{Sn}-7 \mathrm{Zn}-0.006 \mathrm{Al}$. Consequently, Sn-7Zn-0.006Al solder showed the smallest value in heat-softening and the temperature characteristics of $\mathrm{Sn}-\mathrm{Zn}$ alloy can be improved by adding a very small amount of Al.

To determine whether the $Q^{-1}$ peaks appearing in resonant flexural vibration were relaxation phenomena obeying the Arrhenius equation, measurements were carried with non-resonant flexural vibration at low frequencies of 1, 5, 10, 50, and $100 \mathrm{~Hz}$. The results at 1, 10, and $100 \mathrm{~Hz}$ for each solder are shown in Fig. 2. With increasing temperature, the Young's modulus and internal friction decreased and increased in the same manner as

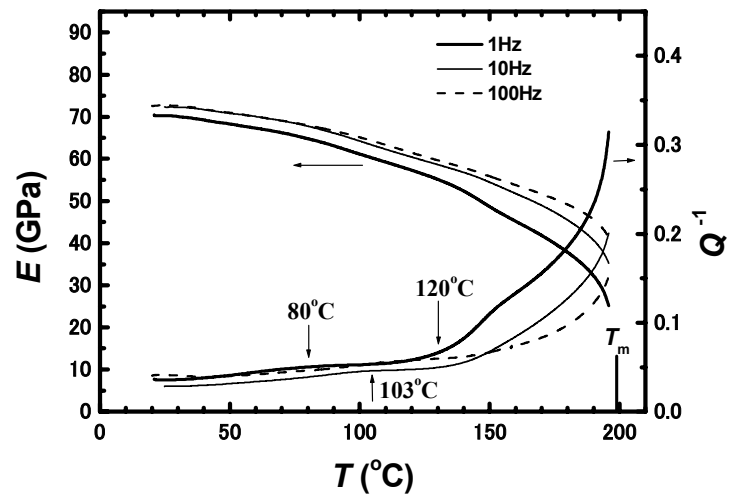

(a) $\mathrm{Sn}-7 \mathrm{Zn}$

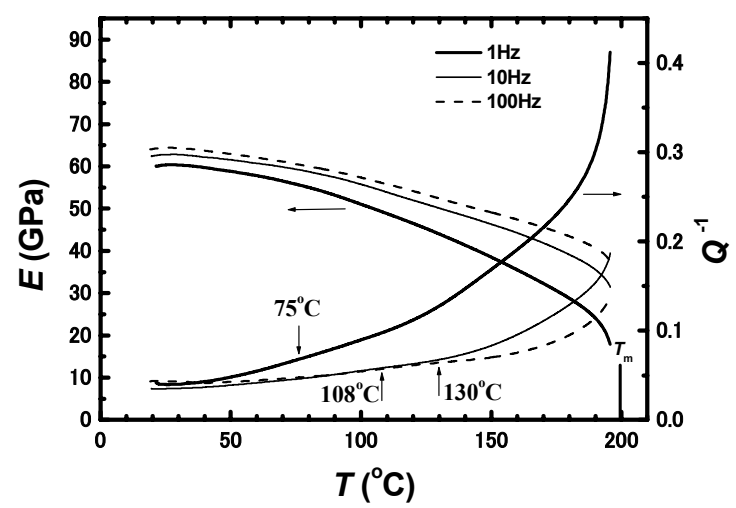

(b) $\mathrm{Sn}-7 \mathrm{Zn}-0.006 \mathrm{Al}$ 


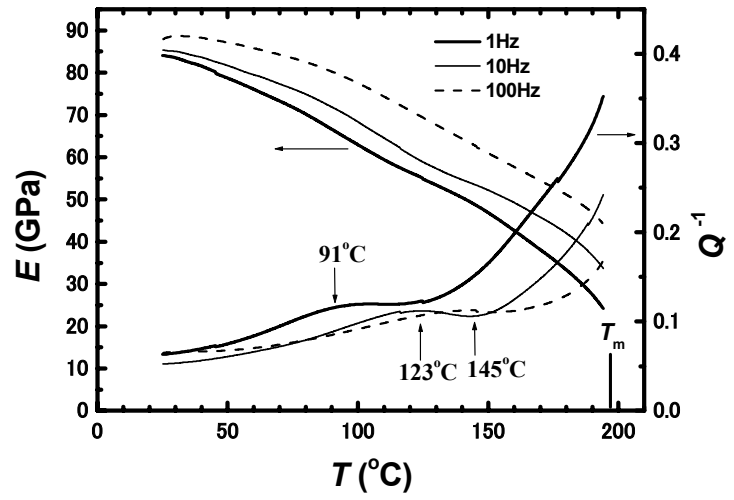

(c) $\mathrm{Sn}-8 \mathrm{Zn}-3 \mathrm{Bi}$

Fig.2 Temperature dependence of Young's modulus $E$ and internal friction $Q^{-1}$ by Dual Cantilever in DMA.

resonant flexural vibration, respectively. In all the solders, a single small peak or shoulder of $Q^{-1}$ appearing at lower temperature with decreasing frequency was observed. In addition, the decrease in Young's modulus and the increase in internal friction with decreasing frequency are due to their frequency dependence ${ }^{(1)}$.

Arrhenius plots were made for the $Q^{-1}$ peaks and shoulders in each solder and shown in Fig.3. The $1^{\text {st }}-3^{\text {rd }} Q^{-1}$ peaks were shown by fine symbols in the lower part of the figure and those at low frequencies by thick symbols. As seen in the figure, in each solder the thick points at low frequencies lay on a straight line, and the $3^{\text {rd }} Q^{-1}$ peak in Sn-7Zn-0.006Al and the $2^{\text {nd }} Q^{-1}$ peak in Sn-7Zn and no fine points in Sn-8Zn-3Bi lay almost on the extension of them. They lying on a straight line were the relaxation phenomena of a same mechanism obeying the Arrhenius equation. The other $Q^{-1}$ peaks at audio-frequencies did not obey the Arrhenius equation, and so their energy loss mechanisms remain a subject for future study. From the slopes of the straight lines, the activation energies of the $3^{\text {rd }} Q^{-1}$ peaks in $\mathrm{Sn}-7 \mathrm{Zn}-0.006 \mathrm{Al}$ and the $2^{\text {nd }} Q^{-1}$ peaks in $\mathrm{Sn}-7 \mathrm{Zn}$, and those at low frequencies in Sn- $8 \mathrm{Zn}-3 \mathrm{Bi}$ were determined to be $83 \mathrm{~kJ} / \mathrm{mol}, 144 \mathrm{~kJ} / \mathrm{mol}$, and $98 \mathrm{~kJ} / \mathrm{mol}$, respectively. Takada et al. (2007) obtained a lower value of $77.1 \mathrm{~kJ} / \mathrm{mol}$ for the activation energy of

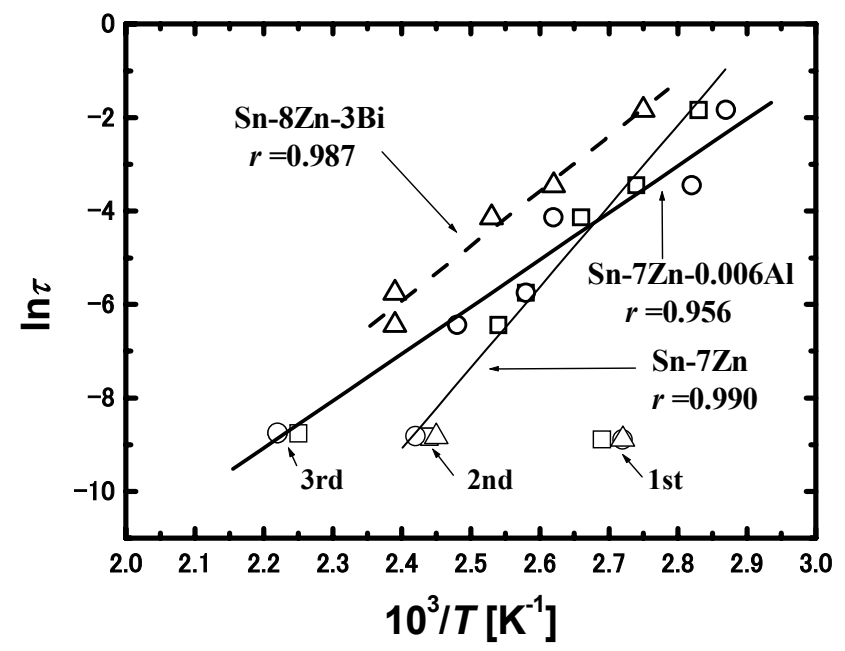

Fig.3 Arrhenius plots for the $Q^{-1}$ peak in Sn-7Zn (square), Sn-7Zn-0.006Al (circle), and Sn-8Zn-3Bi (triangle) solders. 
Sn-8Zn-3Bi solder using a static tensile test ${ }^{(4)}$. This can be explained by the effect of creep.

From activation energy values obtained and former reports of other researchers on metals ${ }^{(2)}$, it was estimated that the origin of these $Q^{-1}$ peaks was related to the grain boundary. The Sn-Zn system forms no compounds, and the alloy elements of Sn and $\mathrm{Zn}$ hardly form solid solutions in each other. In Sn-7Zn solder, a mix of eutectic phase, consisting of $\mathrm{Sn}$ phase and $\mathrm{Zn}$ phase forming comparatively large crystals, is formed surrounding the $\beta$-Sn grain of primary phase as an island. Homma (2005) ${ }^{(5)}$ observed that the bar-form segregation part of the $\mathrm{Zn}$ phase is dispersed and the microstructure is refined, by adding a very small amount of $0.012 \mathrm{Al}$ to $\mathrm{Sn}-9 \mathrm{Zn}$ alloy. Therefore, it was estimated that in $\mathrm{Sn}-7 \mathrm{Zn}-0.006 \mathrm{Al}$, the phase boundary was more coherent by refining the microstructure and the defect became smaller and the activation energy became lower than Sn-7Zn. Thus, $\mathrm{Sn}-7 \mathrm{Zn}-0.006 \mathrm{Al}$ alloy was superior to other $\mathrm{Sn}-\mathrm{Zn}$ system solders in microstructure, and thus $\mathrm{Sn}-7 \mathrm{Zn}-0.006 \mathrm{Al}$ alloy appeared to be superior with regard to mechanical properties.

\section{Conclusions}

The temperature dependence of Young's modulus $E$ and internal friction $Q^{-1}$ in Sn-7Zn-0.006Al solder were investigated comparing with $\mathrm{Sn}-7 \mathrm{Zn}$ and $\mathrm{Sn}-8 \mathrm{Zn}-3 \mathrm{Bi}$ solders, using flexural vibration. (1) $\mathrm{Sn}-7 \mathrm{Zn}-0.006 \mathrm{Al}$ solder showed the highest $E$ in the range of temperatures to $180^{\circ} \mathrm{C}$, representing heat-softenig. The temperature characteristic of Young's modulus in Sn-Zn alloy can be improved by adding a very small amount of Al. (2) Three $Q^{-1}$ peaks appeared at around $90-100^{\circ} \mathrm{C}\left(1^{\text {st }}\right), 135-140^{\circ}\left(2^{\text {nd }}\right)$, and $175-180^{\circ} \mathrm{C}\left(3^{\text {rd }}\right)$ in $\mathrm{Sn}-7 \mathrm{Zn}-0.006 \mathrm{Al}$ and $\mathrm{Sn}-7 \mathrm{Zn}$, and two $Q^{-1}$ peaks at around $90^{\circ} \mathrm{C}\left(1^{\text {st }}\right)$ and $135^{\circ} \mathrm{C}\left(2^{\text {nd }}\right)$ in $\mathrm{Sn}-8 \mathrm{Zn}-3 \mathrm{Bi}$. After performing vibration experiments at low frequencies, from Arrhenius plots for the $Q^{-1}$ peaks in two vibration experiments, the $3^{\text {rd }} Q^{-1}$ peak in Sn-7Zn-0.006Al, the $2^{\text {nd }} Q^{-1}$ peak in $\mathrm{Sn}-7 \mathrm{Zn}$ and those at low frequencies in $\mathrm{Sn}-8 \mathrm{Zn}-3 \mathrm{Bi}$ were relaxation phenomena obeying the Arrhenius equation, whose activation energies were determined to be $83 \mathrm{~kJ} / \mathrm{mol}, 144 \mathrm{~kJ} / \mathrm{mol}$, and $98 \mathrm{~kJ} / \mathrm{mol}$, respectively. (3) It was estimated that the origin of these $Q^{-1}$ peaks was related to the grain boundary, and that in $\mathrm{Sn}-7 \mathrm{Zn}-0.006 \mathrm{Al}$ the phase boundary was more coherent by refining the microstructure due to the addition of $\mathrm{Al}$ and the defect became smaller and the activation energy became lower than in Sn-7Zn. Consequently, Sn-7Zn-0.006Al alloy appeared to be superior to other Sn-Zn system solders in mechanical properties because of excellent microstructure.

\section{References}

(1) Ohoka, T., Nakamura, Y. and Ono, T., Dependence of frequency on Young's modulus and internal friction in Sn-9Zn and Sn-3.5Ag eutectic lead-free solders, Journal of Materials Science, Vol.39 (2004), pp.4379-4381.

(2) Nakamura, Y. and Ono, T., Temperature dependence of anelastic properties in Sn-Ag-Cu system and Sn-3.5Ag alloys of lead-free solders, Journal of Materials Science, Vol.40 (2005), pp.3267-3269.

(3) Kitajima, M., Shono, T., Yamazaki, K. and Noguchi, M., Fundamental physics of Sn-Zn-Al solder (in Japanese), 34th Micro Joining Soldering Subcommittee, Japan Welding Society (2002), pp.41-45.

(4) Takada, A., Sakane, M. and Tsukada, Y., Creep and creep rupture properties of Sn-8Zn-3Bi solder, Journal of the Society of Materials Science, Japan, Vol.56, No.2 (2007), pp.129-135.

(5) Homma, H., Development and the application of Sn-Zn-Al lead free solder, Japan Institute of Electronics Packaging, Vol.8 (2005), pp.404-409. 